\title{
Educação Profissional e Tecnológica:
}

Cotejamentos Entre Brasil e Argentina na Busca do "Novo Desenvolvimentismo"

http://dx.doi.org/10.21527/2237-6453.2020.50.234-253

Recebido em: 30/10/2017

Aceito em: 5/8/2019

\section{Remi Castioni, ${ }^{1}$ Denise Bianca Maduro Silva, ${ }^{2}$ Reinaldo de Lima Reis Júnior ${ }^{3}$}

\begin{abstract}
RESUMO
Este artigo é o resultado do diálogo entre pesquisas que analisam modelos e estruturas da Educação Profissional e Tecnológica (EPT) na contemporaneidade. Escolhemos no presente estudo as trajetórias de Brasil e Argentina, particularmente na última década, quando governos retomaram estratégias de desenvolvimento tendo o Estado como ator principal e conectam-se à estratégia da Comissão Econômica para a América Latina e o Caribe - Cepal - nos anos de 1950/1960, assumindo os desafios da retomada do desenvolvimentismo. A partir das trajetórias históricas das políticas e a análise das instituições de EPT no Brasil e na Argentina, busca-se perceber os caminhos trilhados e os resultados alcançados a fim de se estabelecer possíveis comparações entre a EPT de ambos os países nas últimas décadas, guiando-se a partir dos estudos comparados em educação.
\end{abstract}

Palavras-chave: Educação profissional e tecnológica. Desenvolvimentismo. Políticas públicas. Educação comparada.

PROFESSIONAL AND TECHNOLOGICAL EDUCATION:

\section{COMPARISONS BETWEEN BRAZIL AND ARGENTINA IN SEARCH OF THE “NEW DEVELOPMENT"}

\section{ABSTRACT}

This article is the result of the dialogue between our researches, which analyze models and structures of professional and technological education in contemporary times. In the present article we have chosen the trajectories of Brazil and Argentina, particularly in the last decade, when governments assume development strategies with the State as the main actor, connecting with the Economic Commission for Latin America and the Caribbean - Eclac - strategy in the years 1950/60, facing the challenges of resumption the development. From the historical trajectories and the analysis of the institutions of professional and technological education in Brazil and Argentina, we seek to perceive the ways and results accomplished in order to establish possible comparisons between the professional and technological education of both countries in the last decade, guiding us with the comparative studies in education field.

Keywords: Professional and technological education. Development. Public policies. Comparative studies in education.

\footnotetext{
${ }^{1}$ Doutor em Educação pela Universidade Estadual de Campinas (Unicamp). Professor da Universidade de Brasília (UnB). remi@unb.br

${ }^{2}$ Doutora em Educação pela Universidade Federal de Minas Gerais (UFMG). Técnica em Serviços Educacionais da Universidade Federal de Minas Gerais (UFMG). denisebianca@ufmg.br

${ }^{3}$ Doutor em Educação pela Universidade de Brasília (UnB). Professor do Instituto Federal de Goiás (IFG). reinaldo.Ireis@uol.com.br
} 
O presente artigo, resultado do trabalho coletivo de pesquisa dos autores, visa ao diálogo sobre a Educação Profissional e Tecnológica - EPT - na Argentina e no Brasil, entre os anos de 2003 e 2015. Como mote para o trabalho parte-se do entendimento e verossimilhança da retomada dos estudos e da ação política em torno da concepção mais política dos assuntos econômicos, que é a questão do desenvolvimento, que no início do século 21 ficou demarcado como neodesenvolvimentismo.

Para desenvolver esta temática utiliza-se de revisão bibliográfica e documental e, para narrar os achados, o artigo divide-se em cinco partes. Uma primeira parte dispõe sobre a trajetória do processo de industrialização tardia que envolveu os dois países, seguida, na segunda parte, pela exposição da tradição dos estudos comparados na área da educação, explicitando a escolha metodológica; na terceira parte analisa-se o conceito de desenvolvimento e como foi forjado o neodesenvolvimento; na quarta parte apresenta-se a análise específica sobre a educação profissional e tecnológica da Argentina e do Brasil e, por fim, nas considerações finais, articulam-se esses assuntos. Com a articulação desses elementos, objetiva-se de forma geral, com o presente artigo, meIhor entender as possibilidades e limites que emergem em torno das políticas públicas e estudos que relacionam Estado, educação e desenvolvimento no Brasil e na Argentina, na quadra do capitalismo global.

\section{BRASIL E ARGENTINA: \\ Trilhando Juntos o Caminho da Industrialização Tardia}

O processo histórico de formação do setor produtivo do Brasil e da Argentina percorreu trajetória conjunta na dinâmica do capitalismo. Observado à luz da tese de Prado Jr. (1969) sobre os sentidos da colonização, a região da periferia do sistema tem sua formação social em dependência e influência direta das determinações dos países capitalistas centrais.

Será por meio da criação da Comissão Econômica para a América Latina e o Caribe (Cepal), ${ }^{4}$ em 1948, que o esforço de pensamento intelectual típico da região passou a ganhar envergadura. Raúl Prebisch e Celso Furtado são arautos dessa luta, rompendo com o pensamento liberal reinante que impunha nas teorias das vantagens absolutas a vocação única à agricultura. Deles que emerge a promoção dos Estados Nacionais com vista à inversão da tradição do subdesenvolvimento, estimulando um ciclo de industrialização com forte incentivo à massificação da escolarização.

Somente com Raul Prebisch, então presidente do Banco Central da Argentina, passou a ocorrer uma elaboração de abordagem propriamente latino-americana. Sua alegação era de que os referenciais teóricos eurocêntricos sozinhos não seriam suficientes para entender aos problemas da região. Assim, Prebisch apresentou uma abordagem analítica, passando a ser o referencial dos demais estudiosos da Cepal. A elaboração de uma teoria do processo de desenvolvimento e dos chamados países subdesenvolvidos, com vista ao entendimento da "evolução ou o repensar das teorias do desenvolvimento" (DALLABRIDA, 2011, p. 85), tornou-se a contribuição essencial da Cepal.

\footnotetext{
${ }^{4}$ A Cepal, com sede em Santiago do Chile, contou com apoio de vários países e seus trabalhos procuraram diagnosticar os problemas de cada país em particular, objetivando detectar os obstáculos ao desenvolvimento.
} 
Essa dinâmica é o nascedouro do processo de acúmulo intelectual em torno de uma nova ideia de desenvolvimento, que foi vivenciada no primeiro decênio do século 21. As crises enfrentadas pela Argentina e pelo Brasil, depois da onda neoliberal dos presidentes Carlos Menem/De La Rúa e de Fernando Collor de Mello/Fernando Henrique Cardoso, respectivamente, vão desembocar em governos que fizeram uso de outras estratégias de desenvolvimento, notadamente, entre 2003 e 2015/16, na Argentina e Brasil, Néstor Kirchner e Cristina Kirchner, e Lula e Dilma Rousseff, respectivamente. Mantendo os fundamentos macroeconômicos herdados das políticas neoliberais (câmbio flutuante, política de juros para controle da inflação e superávit primário para pagamento da dívida), os respectivos governos tentaram atenuar os reflexos da crise com políticas de indução ao crescimento econômico baseadas no mercado interno, na expansão de políticas públicas e na retomada do papel do Estado como indutor do desenvolvimento, mediante a geração de empregos, política de valorização do salário mínimo e inserção de contingentes expressivos no círculo do mercado interno de consumo. Mesmo perseguindo rumos novos, no entanto, percebe-se que houve a manutenção dos princípios da horda neoliberal, sobretudo nos elementos articulados com o capital financeiro, em destaque, juros elevados, câmbio flutuante, superávit primário e manutenção de incentivos à entrada de capital via sistema financeiro, mas também se destacaram dois elementos novos: o primeiro é a retomada do debate acadêmico e político do papel do Estado na indução do processo de desenvolvimento nacional e o segundo, centrado em investimentos por meio da formação de poupança. Estes, mesmo limitados pela política fiscal, possibilitaram um ciclo moderado de uma trajetória histórica de crescimento econômico do Produto Interno Bruto - PIB - que articulado com políticas públicas de geração de emprego formal, valorização do salário mínimo, política de distribuição de renda e, em destaque, investimentos por intermédio do Programa de Aceleração do Crescimento (PAC), no caso do Brasil, geraram um ciclo de uma década que começou a impactar na redução da desigualdade social.

Para Rangel (1981), dado que nossa base estrutural se caracteriza por uma dualidade interna da formação socioeconômica, entre um polo moderno e outro atrasado, que interagem na dinâmica do capitalismo mundial, o que se percebe é que a política de Educação Profissional e Tecnológica (EPT) pode atuar com vista à inserção na base moderna de setores sociais excluídos por gerações, agindo na qualificação da margem social da ocupação, mas, também, no polo mais dinâmico, modernizando e gerando tecnologia, possibilitando melhor ingresso da região na disputa global.

Brasil e Argentina em seus processos, participaram da dinâmica global, buscando ao seu feitio de projeto de desenvolvimento, a melhor inserção para prover recursos que possibilitassem saltar a um novo patamar de riqueza social. Prado Jr. (1969) em sua tese sobre "os sentidos da colonização" demonstra como países de base estrutural semelhante e periférica, os casos de Brasil e Argentina, em regra, atuam em seus projetos de desenvolvimento, mais conservando sua condição e nutrindo os países centrais do que no sentido de uma alavancagem a um novo patamar.

Brasil e Argentina enfrentaram, após a década neoliberal de 90, um alargamento de perspectiva de base teórico-política, com retomada de formulações que passaram a ensejar a importância estratégica do Estado visando ao desenvolvimento econômico. Não mais como simples regulador e estimulador da atividade econômico-financeira, 
mas como base estratégica para participação junto a dinâmica global e na articulação macroeconômica interna, com geração de poupança, investimentos e distribuição de renda, objetivando a inversão da desigualdade social. O caso brasileiro se assemelha ao argentino por se aproveitar do fluxo crescente de exportação de commodities para formação de poupança e direcionando para o investimento com forte participação do Estado.

Antes de adentrar especificamente nos processos de expansão da educação profissional e tecnológica dos dois países, cabe introduzirmos duas análises de base teórica e metodológica que sustentam o presente trabalho: a compreensão sobre a evolução da educação comparada e os conceitos e elementos do novo desenvolvimentismo que foram revigorados nos últimos anos na região e, em particular, a ampliação do acesso à educação profissional e tecnológica.

\section{EDUCAÇÃO COMPARADA PARA DESVELAR AS DIFERENÇAS}

Neste trabalho recorre-se à educação comparada como forma de aproximar a análise tanto dos processos históricos e econômicos como sociais, situando o desempenho de Argentina e Brasil. Nesse sentido, entender o desenvolvimento histórico da educação comparada permite assinalar os elementos que a determinam e o enfoque dado ao tema da comparação nas últimas décadas. Os textos aqui selecionados proporcionam uma perspectiva panorâmica do campo e auxiliam a compreender a "questão do método" na educação comparada.

No desenvolvimento histórico da educação comparada como uma episteme (uma ciência) modernista, nas décadas centrais do século 19 - alguns anos seguintes ao que é considerada sua fundação, com Marc-Antoine Jullien de Paris ${ }^{5}$ (1817), que publicou Esboço para um trabalho sobre educação comparada - encontra-se, para Kazamias (2012), a fase denominada "empréstimo", 6 que se caracteriza por um profundo desejo de receber lições úteis de outros países para o transplante das melhores práticas; estava aí presente a ideologia meliorista ${ }^{7}$ de aprimoramento. Segundo Kaloyiannaki e Kazamias (2012), a educação comparada no século 19 tinha a característica de ser um empréstimo seletivo para o transplante visando à fundamentação para reformas. Já conforme Kazamias (2012), eram características dos primeiros estudos: 1) serem similares a relatórios e descritivos, 2) o pensamento utilitário-instrumental e 3) a ideologia meliorista.

Uma próxima fase, que se iniciou a partir da segunda metade do século 19 e irá dominar o campo até meados do século 20, se caracterizou, conforme Kazamias (2012), por um período de domínio de temas histórico-filosófico-culturais e humanistas liberais em educação comparada. Nessa fase entendiam-se os estudos comparados como o estudo da origem e da evolução de sistemas de educação. Assim, nesta segunda fase: “A

\footnotetext{
${ }^{5}$ Para Nóvoa (1995) até 1789 em matéria de comparação predominava a literatura de viagem, que se detinha em contar as práticas que tiveram lugar no estrangeiro.

${ }^{6}$ Alguns analistas incluem Jullien como pertencente a esta fase (KALOYANNAKI; KAZAMIAS, 2012). Apesar da compreensão da importância de Jullien para definição de um programa comparado para a educação, a partir de ideias normativas e da reformulação positivista da educação, neste texto, mais do que interpretações do desenvolvimento do campo da educação comparada centradas nos pioneiros, será seguida a indicação de Schriewer (1996), destacando-se o contexto do campo disciplinar.

${ }^{7}$ Meliorista vem da palavra melhor, ou seja, investigação com o sentido de melhoramento.
} 
educação comparada busca compreender e interpretar a forma como os sistemas nacionais de educação desenvolveram-se para ser o que são; não sendo associada à predição ou orientada à formulação de políticas, ou de aplicação prática" (ibidem. p. 58). Buscavam forças e fatores - políticos, sociais, econômicos e culturais - que influenciaram, produziram, causaram ou determinaram problemas, semelhanças e diferenças em sistemas nacionais de educação ou em alguns de seus aspectos - estruturas, políticas, práticas, etc. Assim entendidos, sistemas nacionais de educação eram consequências de constelações particulares e únicas de forças, fatores e tradições sociais, políticas, econômicas e culturais.

Mattheou (2012) observa que no final da década de 50 a educação comparada estava em busca de uma nova identidade "científica". Destaca que as discussões predominantes no campo da educação comparada nas décadas de 50 e principalmente de 60 eram voltadas para a metodologia. Manteve-se o objetivo ambicioso de explicar o funcionamento da educação e sua relação com o contexto social mais amplo, mas essa compreensão e explicação deveriam basear-se "em uma teoria científica de fundamentos sólidos, em leis abrangentes e em hipóteses quantitativas verificáveis que suportariam testes empíricos exaustivos" (MATTHEOU, 2012, p. 84).

Por sua vez, Nóvoa (1995) considera que diversos autores desta época, ao se dedicarem à definição do método comparativo para uma ciência da educação comparada, atuam segundo os cânones do paradigma positivista, relegando o conteúdo e, portanto, desprezando as referências teóricas e as dimensões ideológicas do trabalho de comparação.

Já em meados da década de 70, no entanto, essa abordagem "científica" começa a desvanecer, na avaliação de Mattheou (2012). Primeiramente porque caíram as crenças em uma única perspectiva científica válida, e, segundo, pelo avanço da perspectiva pós-moderna e da desvalorização das grandes teorias. Como exemplo dessas críticas, Nóvoa (1995) cita quatro pontos fundamentais da educação comparada, baseado em leituras do campo após 1977:

... recusar o Estado-nação enquanto unidade principal de análise; ultrapassar os modelos analíticos "input-output", assim como a utilização exclusiva da quantificação; questionar o funcionalismo estrutural como teoria de referência; definir temas e domínios de interesse novos (NÓVOA, 1995, p. 10).

Para Mattheou (2012), a tendência acadêmica para explorar novos regimes de verdade havia desempenhado seu papel, mostrando-se na atualidade mais importante se falar em educações comparadas.

No entendimento de Nóvoa (1995), quatro aspectos foram essenciais ao campo da educação comparada historicamente: a ideologia do progresso, representada na crença da educação como fator de modernização e desenvolvimento; um conceito de ciência baseado na racionalidade científica comparativa de acordo com o projeto de modernidade social, que será contraposta posteriormente a uma racionalidade alternativa "pós-moderna" que rejeita uma teologia da história; a ideia de Estado-nação, em que a "nação" é vista como uma comunidade política imaginada, e a definição de um método comparativo, com o intento de dar um referente identitário ao campo, mas que acabaria por reduzir as realidades comparadas (p. 11). 
Ainda conforme Nóvoa (1995), três aspectos justificam um novo interesse pela educação comparada nos dias atuais: a existência de problemáticas educativas comuns aos países, suscitadas pela emergência de um sistema mundial nos planos econômico, da educação e da cultura; a crise do Estado-nação e consolidação de novos espaços de identidade local e regional que implicam repensar os lugares tradicionais da tomada de decisão em matéria educativa, e a internacionalização do mundo universitário e da pesquisa científica. Ao mesmo tempo, novos desafios se interpõem à educação comparada na atualidade: construir o objeto de estudo em torno do diálogo entre o local e o global; produzir "...novos modelos de análise que não tomem como referência única dados estruturais, mas que sejam capazes de atribuir sentidos às práticas discursivas dos diferentes atores (individuais, institucionais, políticos) e do modo como elas reorganizam os espaços e os sentidos da educação a nível nacional e internacional" (NÓVOA, 1995, p. 23, grifo do autor) e alargar o repertório metodológico.

No diálogo entre o local e o global, situados na emergência do sistema mundial em nível econômico, da educação e da cultura, é que damos início ao exercício da comparação. Enfocaremos, a seguir, referências teóricas e ideológicas comuns ao neodesenvolvimentismo de Brasil e Argentina, passando, na sequência, à análise detida da EPT, com atenção ao nível médio técnico, em cada país, entre 2003 e 2015, para, ao final, apreender as implicações desses processos institucionais e políticos para a região.

\section{A TEORIA POR DETRÁS DOS INVESTIMENTOS: Um Novo Desenvolvimento?}

Para Gambina (2013), sobretudo por sua importante produção em torno da análise crítica do sistema capitalista, o surgimento alardeado de um "novo" desenvolvimento não é recente nos meios intelectuais e políticos da América Latina, datando de meados do século 20 as propostas de superação dialética do subdesenvolvimentismo para o desenvolvido, de dominado para dominador. O conceito de desenvolvimento ficou consagrado na trajetória histórica, seja no campo da pesquisa científica, seja nas disputas políticas, diretamente relacionado com crescimento econômico. (DALLABRIDA, 2011).

Seguindo com a caracterização que formulou Bresser-Pereira (2016), o desenvolvimento pode ser pensado de duas perspectivas: uma que se define como forma de organização econômica e política para o capitalismo distinta do liberalismo e a outra que se assenta como uma escola de pensamento econômico.

De acordo com Bresser-Pereira (2012), na atual quadra do capitalismo globalizado em que se alardeia a eficiência do mercado, é mais que urgente que os Estados adotem estratégia nacional de desenvolvimento, sendo “(...) um conjunto de valores, ideias, leis e políticas orientadas para o desenvolvimento econômico que leva à criação de oportunidades para que empresários dispostos a assumir riscos possam investir e inovar" (Ibidem. 2012, p. 29).

A estratégia nacional de desenvolvimento deveria ter implicado ações de incremento na base material da produção, mas também formulações institucionais do Estado, devendo ter como premissas: aumento de poupança e de investimentos; medidas que incentivem a incorporação do progresso técnico na produção; valorização do capital humano; geração de coesão social e capacidade de geração de uma política macroeconômica articulada com a saúde financeira do Estado (BRESSER-PEREIRA, 2012). 
Por sua vez, Katz (2014b) afirma que o debate intelectual em torno do novo desenvolvimento é multifacetado, tanto no Brasil como na Argentina, mas é possível elencar cinco fundamentos gerais que se fazem presentes nas controvérsias dos autores, sendo eles: (i) os autores surgem no nicho da avalanche neoliberal e suas interpretações consensuais que perfilaram os cânones acadêmicos e governamentais do último quarto do século passado, assim em suas formulações apresentam pormenorizadamente a maior participação e intervenção do Estado para emergir do subdesenvolvimento; (ii) os neodesenvolvimentistas entendem que é a política econômica um instrumento central na via do crescimento, não estando somente refém da conjuntura, ela deve estar a serviço do planejamento de longo prazo; (iii) os neodesenvolvimentistas entendem que o processo de crescimento deve estar vinculado à retomada de uma política de industrialização; (iv) em torno do seu planejamento, reduzir a brecha tecnológica é mais um ponto das suas políticas, retornando sobretudo aos pressupostos de Schumpeter e (v) o avanço exportador do sudeste asiático é uma análise a ser observada como suporte de referência de aprendizado, presente nas estratégias de Estado para estimular a competição.

Países como Brasil e Argentina precisam conseguir pôr em prática um processo de desenvolvimento bilateral. Da mesma forma que trabalham com processos de inclusão social de uma gigantesca massa populacional excluída de direitos mínimos, têm inequivocamente que ampliar os setores de desenvolvimento de tecnologia de ponta, o que deve ocorrer no mesmo sentido de uma maior participação dos setores sociais, não mais exclusivos de uma minoria. O momento histórico e as necessidades específicas de Brasil e Argentina distinguem-se, portanto, do processo europeu ocorrido em meados do século 20.

Ao situar o novo desenvolvimentismo a partir dos governos Lula/Dilma Bresser-Pereira (2015) destaca que estes governos estavam efetivando aquilo que havia sido consagrado na Constituição Federal de 1988, o desenvolvimentismo social. Os governos do PT estariam materializando o desenvolvimento social previsto, rompendo com isso com o liberalismo que se seguiu após 1988 até o início do século 21. Segundo este autor (op. cit., p. 28), “...Não é portanto, um conceito histórico, mas um conceito normativo". Assim sendo, a combinação de fatores previstos na ortodoxia liberal, com elementos de políticas industriais, política de câmbio e proteção social, são as bases de sustentação do novo desenvolvimentismo, que tratam de desenvolver a economia de forma plena, integrando os cidadãos a partir dos seus direitos sociais consagrados na Constituição Federal de 1988.

Isso posto, tanto políticas públicas de Estado no Brasil e na Argentina procuraram equacionar o déficit fiscal com distribuição de renda. Há uma participação induzida fundamental do Estado no ensejo de acesso e melhorias de escolarização como direito. Assim, o que se teria é um novo elemento: em um processo de crescimento econômico relacionado com distribuição de renda, em médio prazo, o Estado entra como indutor na geração e acesso à escolarização, visando com isso a ampliar o capital social que está buscando o mercado de trabalho. É por essa conexão explicitada que, na sequência, ao apresentarmos as iniciativas federais na educação técnico-profissional para os casos de Brasil e Argentina, elegemos focalizar no nível médio técnico tanto pelos vultosos investimentos na modalidade, ocorridos no período em análise, como por se tratar de um nível de ensino que passará a contar com leis e políticas públicas tendentes à garantia do 
maior acesso pela população, como também exigências do novo ciclo de produção, que demandam uma mão de obra mais bem qualificada. Dessa forma, o emprego de pessoas com formação profissional adequada contribuiria para que usufruíssem do novo ciclo de produção.

\section{OS INVESTIMENTOS NA EPT: Marcas de um Novo Signo?}

\section{Que caminhos percorreu a Argentina?}

Para caracterizar a educação técnico-profissional argentina, inicialmente discute-se de forma breve a história e a estrutura de ensino neste país, para assim poder compreender melhor o que motivou e o que representaram as mudanças ocorridas na área entre 2003 e 2015, com destaque para as ações dos governos nacional-desenvolvimentistas.

Os primeiros passos da educação técnica na Argentina datam de fins do século $19,{ }^{8}$ mas foi em função da Segunda Guerra Mundial que a Argentina passa a agregar valor à sua matéria-prima e iniciam-se os trabalhos que impulsionaram o desenvolvimento da educação técnica que terá seu ápice entre nas décadas de 60 e 70 . Segundo Gallart (2006), o ensino técnico-profissional na Argentina nasce com o duplo propósito de levar aos alunos uma educação que lhes permitisse se inserir no mundo do trabalho como profissionais mais qualificados e também de prepará-los para os estudos de nível superior, normalmente dirigidos para profissões com forte conteúdo técnico, como as Engenharias e a Arquitetura. A partir desse pressuposto e analisando a trajetória de egressos da Educação Técnico-Profissional, a referida autora argumenta que esta sempre foi vista e vivida como forma de mobilidade ocupacional ascendente pelas novas gerações.

Sosa (2016b) considera que o desenvolvimento da Educação Técnico-Profissional, alinhada às transformações produtivas do país, pode ser dividido em três momentos distintos: o primeiro vai desde 1930 a 1975, constituindo seu momento de criação e estruturação, como já mencionado; o segundo, de 1976 a 2001/02, de alinhamento às políticas globalizadas na área de EPT, como explicitado a seguir pelos resultados perceptíveis nos anos 90, e o terceiro momento de 2003 a 2014, discutido ao final dessa seção, ao qual adicionamos o ano de 2015.

Nos anos 90 o que se vê, na prática, é a destruição da educação técnica: foi dissolvido o Consejo Nacional de Educación Técnica - Conet, ${ }^{9}$ órgão central responsável pelas escolas técnicas, as instituições passaram a depender das jurisdições (governos locais) e surge o slogan de que "uma escola técnica deve valer-se por si mesma", ou seja,

\footnotetext{
${ }^{8}$ No ano de 1898 foi criada a seção industrial da Escuela Nacional de Comercio, considerada a primeira escola industrial argentina (Escuela Otto Krause).

9 O Ministerio de Educación y Justicia de la Nación cria escolas técnicas e de formação em ofícios, paralelamente cria organismos especializados para condução e supervisão das escolas. Assim, pelo Decreto $N^{\circ} 14.538 / 44$, cria-se a Comisión Nacional de Aprendizaje y Orientación Profesional (CNAOP) que, posteriormente, se funde à Dirección Nacional de Enseñanza Técnica, dando origen ao Consejo Nacional de Educación Técnica (Conet), criado como uma autarquia mediante a Lei № 15.240 de 1959. Dando continuidade aos trabalhos do Conet nos anos 90 surgirá o Inet, responsável pelo desenho, instituição e acompanhamento das políticas nacionais para educação técnicaprofissional, mas sem ter uma rede própria de escolas técnicas sob sua coordenação (OTERO, 2014).
} 
deve produzir seus meios de financiamento, como testemunha Hector Cova, Secretario General de la Asociación del Magistério de Enseñanza Técnica - Amet/Capital (METRO, 2015). Ademais, o currículo do ensino técnico perde sua especificidade, como argumenta Ferreira (2012). Influi nesse sentido o perfil da matriz econômica adotada nos anos 90, quando o país focou na geração de serviços, deixando um ensino conectado a um projeto de industrialização relegado a um segundo plano. Nesse contexto de falta de investimentos financeiros e político-pedagógicos se fecharam ou se transformaram em escolas de formação geral várias das escolas técnicas.

A partir de 2005, porém, a Argentina passa a acompanhar a aposta na Educação Profissional e Tecnológica como estratégia de desenvolvimento, considerando a educação para o mundo do trabalho como motor produtivo e forma de inclusão social.

Antes mesmo da nova Lei de Educação Nacional - $\operatorname{LEN}^{10}$ (N. 26.206, de 2006), considerada um verdadeiro ato de mudança com o consenso reformista dos anos 90 (SAFOCADA; VASSILADES, 2011), promulgou-se na Argentina uma base normativa para sustentar a política pública nessa área. É a Lei de Educação Técnico Profissional - Lei de $\operatorname{ETP}$ (N. 26.058/2005), que veio para recuperar a EPT ${ }^{11}$ (OTERO, 2011).

En ese marco, se recuperó la Educación Técnico Profesional con la firme decisión política de dar apoyo a la inclusión, permanencia y terminalidad de las trayectorias formativas de los estudiantes, así como su inserción en un nuevo contexto socioproductivo de país, orientado a la industrialización, el empleo y la justicia social (ARGENTINA, 2015a, p. 7).

Espero que nunca más se piense que la Argentina puede ser meramente un país de servicios. Dios quiera que las escuelas que conocimos de chicos, que eran de artes y oficios, después escuelas técnicas, que tantas satisfacciones nos dieron a los argentinos, puedan rápidamente ser puestas en marcha (presidente Néstor Kirchner no ato de promulgação da Lei de ETP, 8 de setembro de 2005, apud ARGENTINA, 2015a, p. 14).

A EPT na Argentina inclui as escolas técnicas de nível médio, ${ }^{12}$ as instituições de educação técnico-profissional de nível superior, onde se formam os técnicos superiores, e as instituições de formação profissional, nas quais se oferece a formação continuada para o mundo do trabalho, contemplando 3.080 instituições $^{13}$ em 2015 (ARGENTINA,

\footnotetext{
${ }^{10}$ Destaca-se que a LEN tornou o Ensino Médio obrigatório. Com a Lei 27.045 de 2014, a educação passa a ser obrigatória a partir dos 4 anos de idade, totalizando 14 anos de escolaridade obrigatória. Para Miranda e Corica (2014), ao contrário dos anos 90, o que se viu a partir de 2003 foi um quadro de ampliação das políticas sociais com a Ley de Educación Nacional de 2006, a aplicação de controles sobre o trabalho infantil e a AUH- Asignación Universal por Hijo - em 2009.

${ }^{11} \mathrm{Em}$ 2014, por meio da Resolução n. 234/14 do Consejo Federal de Educación, passados 10 anos da Lei de ETP, declarou-se o dia 7 de setembro como Dia da Recuperação da Educação Técnica.

${ }^{12} \mathrm{O}$ Ensino Médio inclui um ciclo básico comum a todas modalidades de dois ou três anos de duração, depende se o sétimo ano da Educação Básica está localizado no Ensino Médio ou primário, o que é uma possibilidade prevista na lei, e um ciclo orientado com caráter diversificado, de três anos de duração no ensino comum e de quatro anos de duração no caso da modalidade técnico-profissional. Assim, o Ensino Médio Técnico pode ter entre 6 e 7 anos de duração, dependendo da localidade (Dirección Nacional de Gestión Curricular y Formación Docente, 2016).

${ }^{13}$ São instituições também constantes no Registro Federal de Instituiciones de Educación Técnico Profesional - RFIETP, no ano de 2015, consideradas de outros níveis e modalidades mas que ofertam a educação técnico-profissional: de ensino médio comum orientado (137), formação docente (420), educação artística (45), educação especial (234), educação permanente de jovens e adultos (439) (ARGENTINA, 2015b). RFIETP é a base de dados na qual se inscrevem as instituições abarcadas pela Lei de ETP n. 26.058/05, que tem por objetivo favorecer a melhoria dessas instituições e dar garantia pública de que esses estabelecimentos cumprem com os critérios federais de qualidade.
} 
2015b). Em detalhes, entre 2006 e 2014 houve um aumento de 82,7\% no número de instituições educativas registradas que ofertam EPT (incluindo as de educação técnico-profissional e as que são de outra modalidade, mas ofertam educação técnico-profissional), passando de 1.054 instituições de nível médio para 1.588 (aumento de 50\%), de 176 instituições técnicas de nível superior para 489 (178\% de aumento), de 661 instituições de formação profissional para 947 (43\% de aumento) e de 520 instituições consideradas de outros níveis e modalidades que ofertam a educação profissional para 1.380 (165\% de aumento) (ARGENTINA, 2015c). Segundo o mesmo documento, a evolução das matrículas entre 2003 e 2013 mostra um aumento no número de alunos no nível superior técnico (de 134.828 para 193.857 , aproximadamente $44 \%$ de crescimento), no nível médio técnico (de 488.243 para 611.202, aumento de aproximadamente $25 \%$ ) e na formação profissional (de 258.617 para 303.591, aumento de aproximadamente 17\%).

Analisando apenas o Ensino Médio técnico, o número de matrículas em 2011 em relação a todas as matrículas no Ensino Médio, ${ }^{14}$ na Argentina $(15,2 \%)$, é pequeno se comparado com a média dos países da $\operatorname{OCDE}(45,7 \%)$, mas ainda é maior do que no Brasil (14,2\%). Reafirmando a força dos investimentos públicos na EPT, destaca-se que há prevalência de escolas técnicas estatais de nível médio na Argentina, 90\% de todas as escolas técnicas; quantitativo muito maior do que a prevalência de escolas estatais entre as escolas não técnicas, aproximadamente $68 \%$.

Figura 1 - Matrículas no nível médio na Argentina por modalidade e tipo de oferta, ano de 2015

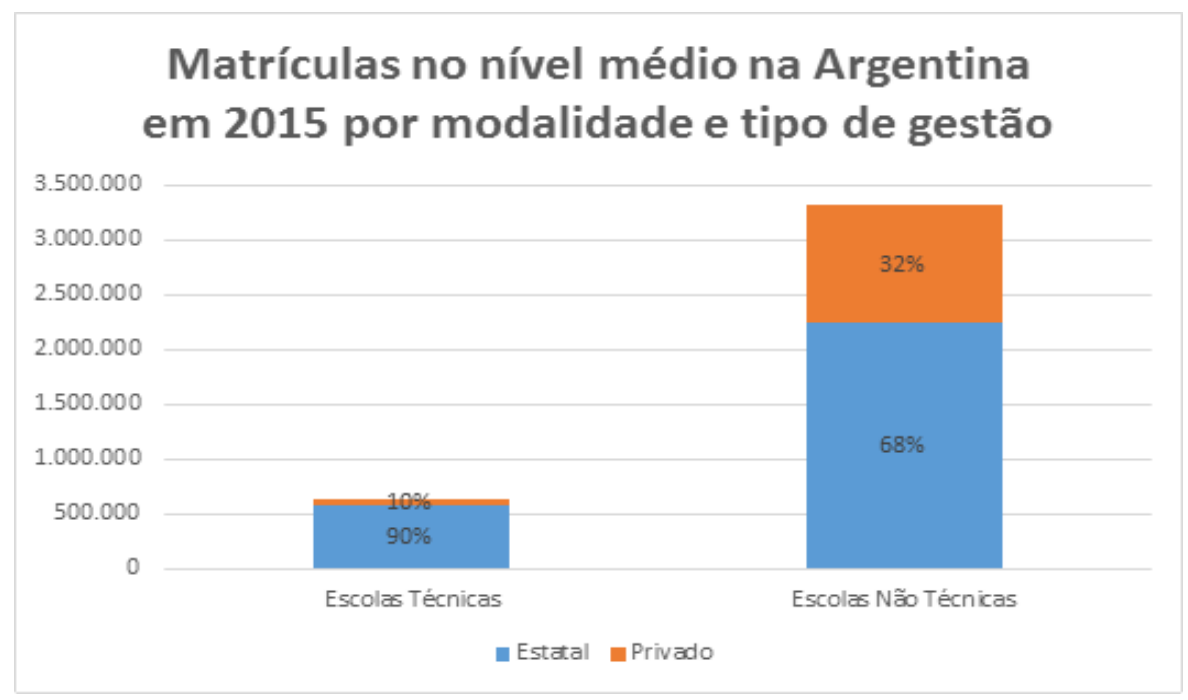

Fonte: Relevamiento Anual 2015. DiNIEE. Ministerio de Educación - Argentina. Nota: 'Escolas técnicas' corresponde às instituições de nível médio constantes e 'escolas não técnicas' às instituições de nível médio não constantes no Registro Federal de Instituciones de Educación Técnico Profesional - RFIETP em 30/6/2013. Data de extração: 2/6/2016.

\footnotetext{
${ }^{14}$ OECD (Organisation for Economic Co-operation and Development) 2011 and 2012. Education GPS: The World of Education at Your Fingers. OECD Education GPS website, http://gpseducation.oecd.org
} 
A Lei de ETP cria o Fondo de Mejora Contínua para la Educación Técnico Profesio$n a l^{15}$ (estabelece $0,2 \%$ das receitas correntes do setor público do orçamento anual nacional para a educação técnico-profissional) com o propósito de garantir o investimento necessário para a melhoria da qualidade das instituições de ETP, prevendo linhas de ação nacional, sob a forma de Programas Federais e Planos de Melhora. Na Argentina, ainda que a responsabilidade de gestão da educação de nível médio, técnica ou não, seja descentralizada, destacam-se a partir de 2005 as políticas financiadas com recursos nacionais sob responsabilidade do Instituto Nacional de Educación Tecnológica - Inet do Ministério da Educação, principalmente a operacionalização dos Programas Federais e avaliação e acompanhamento dos Planos de Melhoria ${ }^{16}$ jurisdicionais e institucionais baseados em diagnósticos das realidades educativas; programas federais e planos de melhoria jurisdicionais e institucionais que representaram entre 2006 e 2014, respectivamente, $11,9 \%, 39,2 \%$ e $48,8 \%$ de um total de $\$ 5.841 .545 .106^{17}$ (ARGENTINA, 2015b). Os Programas Federais e os Planos de Melhoria (um total de 19.222 planos institucionais e jurisdicionais, entre 2006-2014) seguiam linhas de ação voltadas para atendimento a alunos (compreendia ações do Programa Igualdad de Oportunidades, financiando mochilas técnicas, transporte de estudantes, equipamentos para albergues estudantis, acompanhamento pedagógico, inovação pedagógica, etc.), oficinas móveis para aulas de campo (estruturas transportáveis para capacitação em diversas especialidades), docentes (ações de formação docente inicial, continuada e capacitações específicas), entorno educativo (equipamentos e insumos), infraestrutura (novos edifícios, ampliações e reformas, além de melhorias nas condições de segurança e higiene), e Tecnologias da Informação e Comunicação - TICs (ARGENTINA, 2015a); linhas estas que receberam respectivamente, entre 2006 e $2014,12,6 \%, 4 \%, 7,9 \%, 42,7 \%, 23,1 \%, 9,7 \%$ de um montante de \$5.841.545.106, ainda que houvesse variação na ênfase de investimento em cada ano compreendido no período (ARGENTINA, 2015b). Registra-se no período a construção de 30 novos edifícios de EPT (ARGENTINA, 2015a).

Também modificou-se curricularmente a educação secundária técnica ao aumentar o número de horas práticas e a Comisión Federal de la Educación Técnico Profesional delinear 22 marcos de referência, entre 2007 e 2011, para homologação em âmbito nacional de títulos de técnicos de nível médio, definindo o alcance do perfil profissional e a trajetória formativa em termos gerais, científico-tecnológico, técnica específica e prática profissionalizante (ARGENTINA, 2017). Ademais, construiu-se o Catálogo Nacional de Títulos y Certificados de Educación Técnico Profesional, que informa aos interessados nesta modalidade sobre os certificados e títulos de educação técnico-profissional e suas

\footnotetext{
${ }^{15}$ Outra legislação de fundamental importância para o financiamento foi a Lei de Financiamento Educativo (26.075, de 2005) que incrementa a participação relativa da nação no orçamento consolidado destinado à educação, ciência e tecnologia até alcançar $6 \%$ do PIB, o que levou ao aumento do investimento em infraestrutura e equipamentos das escolas e centros de formação profissional. Em 2015 o percentual aplicado na educação era de 6,2\% do PIB (ARGENTINA, 2015a).

${ }^{16}$ O Plano de Melhoria para o ensino médio, em geral, foi criado em 2010, para reformas das condições materiais, estruturais, tecnológicas, pedagógicas, institucionais e para novos planos curriculares, com o propósito de melhorar a qualidade do ensino e acompanhar as trajetórias pedagógicas dos estudantes (FELDFEBER; GLUZ, 2011). Abrangendo todo o Ensino Médio, técnico ou não, destaca-se também o programa federal Conectar Igualdad, que entregou notebooks para cada aluno e docente de escolas públicas de educação básica, junto com o desenvolvimento de conteúdos digitais.

${ }^{17}$ Valores em peso argentino.
} 
ofertas formativas em todo o país. Em 2015 existiam 17.077 Planos de Estudos distintos registrados no referido Catálogo, dos quais 2.519 para o nível médio técnico, 1.041 para o ensino superior técnico e 13.517 de formação profissional, considerados cursos de qualificação (ARGENTINA, 2015b).

Entre as ações coordenadas pelo Inet destaca-se a estratégia federal de acompanhamento pedagógico dos estudantes com matérias dependentes de aprovação na educação técnica profissional de nível médio, instituído em 2013 pela Resolução $n$. 208/13 do Consejo Federal de Educación, e que é denominada Estratégia Federal para la Finalización de Estudios Técnicos de Nivel Secundario - FinEsTec - por ser parte do Plano de Finalização de Estudos Primários e Secundários (Plan FinES), financiado pelo Banco Mundial. O FinEsTec em 2014 contava com 2 mil egressos e 866 escolas participantes (ARGENTINA, 2015a).

Como resultado dos debates gerados a partir do FinEsTec, o Inet construiu um marco para Evaluación de Capacidades Profesionales en la Educación Técnico Profesional de Nivel Secundario destinado a contribuir com os docentes deste nível e modalidade de ensino quanto aos processos de avaliação de saberes e competências profissionais (ARGENTINA, 2015d).

Também foi desenvolvida no Inet a Estratégia Federal de Autoevaluación Institucional, em que diretores, docentes e alunos identificam suas fortalezas e debilidades para o desenvolvimento de seus projetos educativos. Em 2015 a estratégia envolvia 531 escolas, 62.610 alunos e 34.298 docentes (ARGENTINA, 2015a).

A aposta na EPT também redefiniu estratégias dentro do Inet (ARGENTINA, 2011, 2015e), que contou com investimento do Banco Mundial por meio do Sistema de Seguimento de Egresados de la Educación Tecnico Profesional de Nivel Secundário - SEGETP. Este consiste em um sistema de coleta de informações que envolveu um censo dos alunos de último ano do Ensino Médio Técnico em 2009 e o segmento amostral desses egressos na perspectiva dos itinerários formativos escolhidos e na inserção no mercado de trabalho. Na atualidade estão trabalhando no desenvolvimento de um censo envolvendo todos os anos do Ensino Médio Técnico. $O$ trabalho da equipe de pesquisadores do Inet, amplia as possibilidades de suas bases de dados para subsidiar as políticas públicas nacionais dirigidas à área.

Em alinhamento com os estudos de Maduro Silva (2018), em sua tese doutoral, percebe-se que para o período de 2003 a 2015 o Estado argentino retomou em parte o papel de indutor de políticas públicas para a educação técnico-profissional, por meio do financiamento, da definição de normativas e programas nacionais, alinhados à avaliação. Em específico, sobre o Ensino Médio Técnico, além de ser pensada a melhoria da qualidade de sua oferta em um contexto de retomada da produção nacional, também carrega características inclusivas, com a determinação de sua obrigatoriedade e programas voltados para a permanência ou para trazer de volta os estudantes à escola. 


\section{E NO BRASIL?}

Reflexos da Estratégia Estatal e o Novo Desenvolvimentismo na EPT

A ampliação da Rede Federal de Educação Profissional e Tecnológica (Rede) está em sintonia com o projeto do novo desenvolvimento que foi delineado a partir do governo Lula. Pensou-se e levou-se a cabo um programa robusto de ampliação da rede federal de EPT para que estivesse presente em todos os Estados do país, mais direcionado para pequenos e médios municípios - quase $70 \%$ dos campi instalados - e nas regiões metropolitanas, particularmente nas zonas de periferia (REIS JR., 2017).

A criação dos Institutos Federais pela Lei no 11.892/2008 demarca uma nova etapa que se propõe em sintonia com as necessidades da formação na modalidade de EPT. Esta ação foi decorrente do lançamento de um ambicioso programa em 2007 denominado de Plano de Desenvolvimento da Educação - PDE - que previu forte elevação dos investimentos em educação, da creche à Pós-Graduação, sintetizadas em um conjunto de 42 medidas para efetivar uma plataforma de melhorias na educação brasileira, isso em plena vigência do I Plano Nacional de Educação (2001-2010), estabelecido pelo governo Fernando Henrique Cardoso, que embora contivesse metas audaciosas, não foi efetivado porque não havia previsão de investimento equivalente. O PDE teria sido uma recomendação expressa do presidente Lula ao seu ministro Fernando Haddad, logo no início do seu segundo mandato, em 2007.

Além disso, o governo Lula, desde a campanha eleitoral de 2002, tinha como compromisso rever o marco legal da educação profissional, personificada pelo Decreto $\mathrm{n}$ 2.208, de 17 de abril de 1997, que foi introduzido pelo seu antecessor, Fernando Henrique Cardoso, e cuja principal medida foi a separação da parte acadêmica do Ensino Médio do Ensino Técnico, o que causou grande reação, principalmente das escolas técnicas que tiveram de se adaptar e viram seu prestígio ameaçado, uma vez que eram reconhecidas pela qualidade dos seus cursos. A separação fora uma exigência do financiamento concedido pelo Banco Interamericano de Desenvolvimento - BID. Em 2004 o Decreto no 5.154 revogou o Decreto no 2.208/1997, o que permitiu novamente a integração do Ensino Médio ao Ensino Técnico e foi a base de lançamento de uma nova plataforma para a educação profissional. Com ele o governo Lula agradou os críticos ao revogar a separação, enquanto lançou as bases de uma robusta expansão, que representou a contratação de 40 mil novos quadros entre professores e funcionários. A criação dos Institutos Federais, no que respeita à formação de técnicos de nível médio, integrados ao Ensino Médio, buscou uma perspectiva de dupla integração: a formação profissional com a propedêutica de tempo integral. Os Institutos estabeleceram um novo marco à EPT, colocando-a em igualdade de interesse com as escolas regulares e com a universidade, uma vez que abarcam desde a formação inicial e continuada, passando pelo Ensino Médio Técnico, até a formação superior e em Pós-Graduação. A criação dos Institutos Federais permitiu também a presença do governo federal em várias regiões do país e a possibilidade de firmar alianças com os territórios locais, sem passar pelo crivo dos Estados, na sua maioria de oposição ao governo federal. Além disso, o governo federal contou com os Institutos para promover uma série de ações complementares a determinadas políticas, como beneficiários do Bolsa Família, do Programa Seguro-De- 
semprego, etc. Os Institutos Federais passaram a ser operadores de políticas públicas desenhadas por vários ministérios, entre eles o Ministério do Desenvolvimento Social, da Pesca, da Saúde, etc.

Esse panorama trouxe à Rede Federal uma nova capilaridade de atuação que, por meio do Plano de Expansão da Rede Federal de Educação Profissional e Tecnológica, ${ }^{18}$ passou de 140 unidades no território brasileiro, no início do governo Lula, para 354 unidades em 2010, cobrindo, pela primeira vez, todas as regiões e Estados do país (BRASIL/ SETEC, 2013). Continuando o vertiginoso crescimento, novas unidades dos Institutos Federais de Educação, Ciência e Tecnologia foram inauguradas e outras ampliadas e em 2016 somavam 644 unidades na Rede Federal, sejam elas Institutos Federais, Centros Federais de Educação Técnica (Cefets), Universidades Tecnológicas ou Escolas Técnicas vinculadas às universidades, todas instituições voltadas, entre outros níveis de ensino, para o incremento da qualidade do Ensino Médio direcionado para o mundo do trabaIho e o desenvolvimento da ciência e da tecnologia.

Figura 2 - Expansão da Rede Federal em unidades (1909-2016)

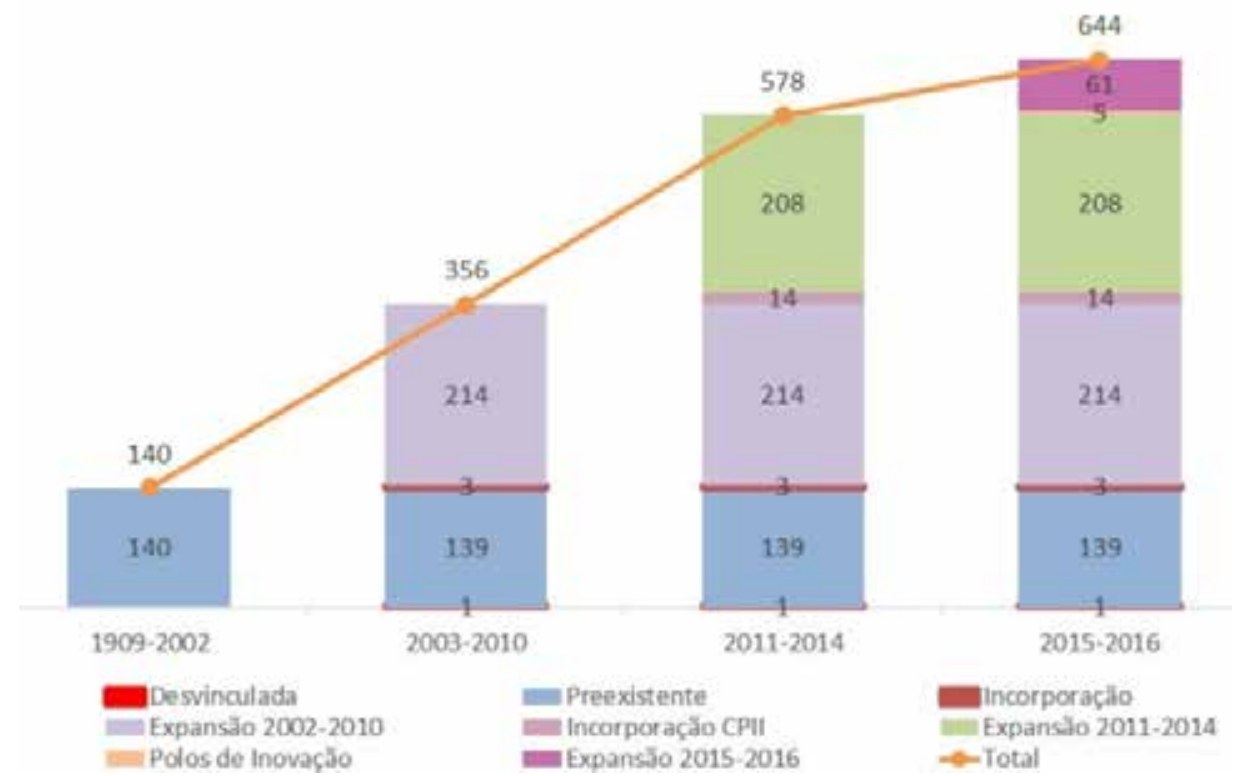

Fonte: http://redefederal.mec.gov.br/expansao-da-rede-federal, citado por Moraes e Kipnis (2017).

Para além da Rede própria de EPT, no relatório de gestão referente ao ano de 2013 (BRASIL, 2013), a Secretaria de Educação Profissional e Tecnológica do Ministério da Educação (Setec/MEC) traz informações importantes sobre a colaboração com os entes federados e, sobretudo, demonstra como tinha direcionado sua política às distintas regiões do país, por meio do Programa Brasil Profissionalizado. ${ }^{19}$ No ano de 2012, de

\footnotetext{
${ }^{18}$ Documento produzido pelo Ministério da Educação, no Centenário da Rede Federal de Educação Profissional e Tecnológica, em 2009.

${ }^{19}$ Programa Brasil Profissionalizado foi criado no ano de 2007, pelo decreto no 6.302 e tinha por objetivo "estimular o ensino médio integrado à educação profissional, enfatizando a educação científica e humanística, por meio da articulação entre formação geral e educação profissional no contexto dos arranjos produtivos e das vocações locais e regionais", investindo recursos federais em obras escolares dos sistemas estaduais.
} 
acordo com o documento, 744 obras integravam o Programa, dessas, 331 somente no Nordeste, correspondendo a 44,48\%. Já a região Centro-Oeste detinha 141 obras que integravam o Programa, aproximadamente $18,95 \%$ do total.

A contínua expansão dos investimentos na EPT deve-se também ao novo Plano Nacional de Educação aprovado no final do primeiro governo Dilma (BRASIL, 2014a), por meio da Lei no 13.005/2014, que na sua Meta 11 estabelece a proposição de triplicar as matrículas da educação profissional técnica de nível médio e que, destas, $50 \%$ das matrículas estejam na educação pública.

Figura 3 - Número de Matrículas (em milhares) na Educ. Profissional no Ens. Médio Integrado à Educ. Profissional e na Educação de Jovens e Adultos Integrada à Educação Profissional de Nível Médio

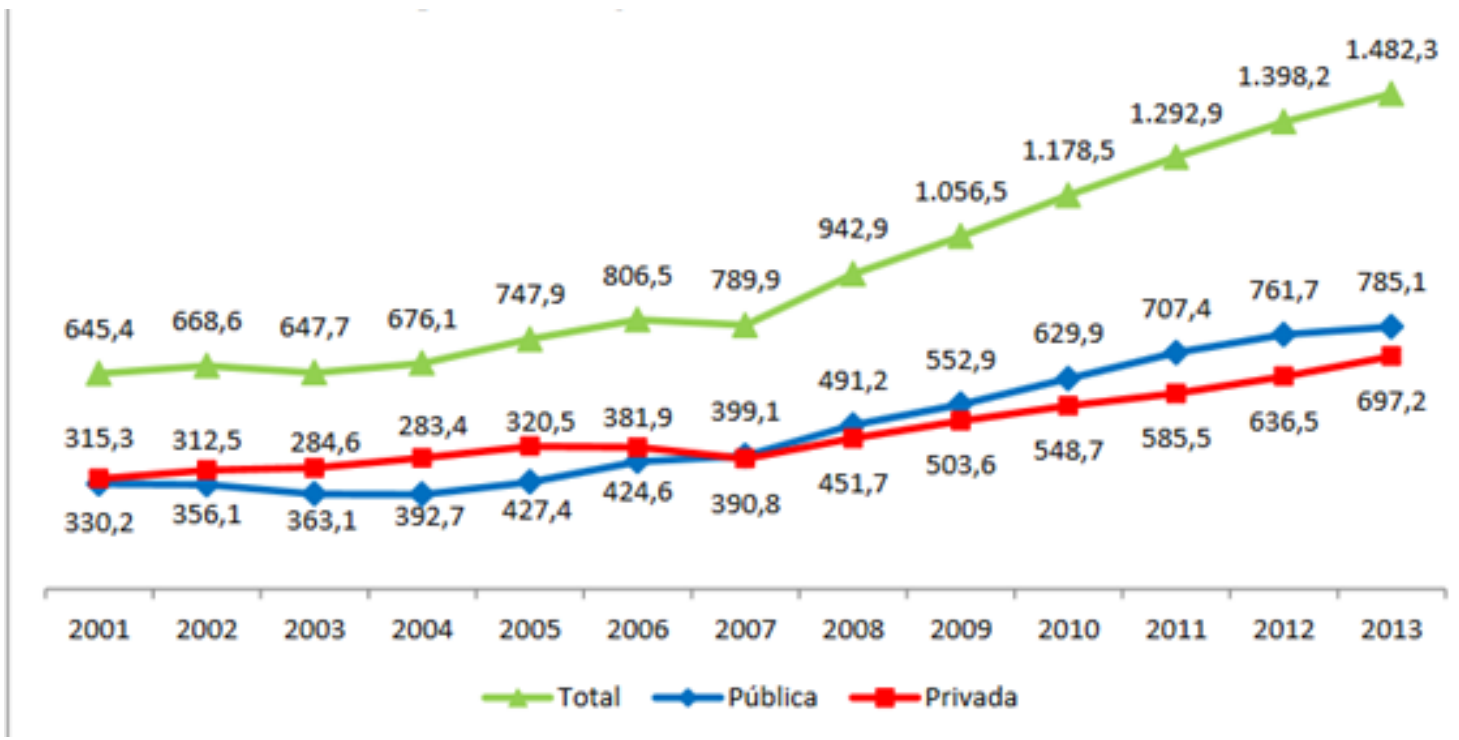

Fonte: Compilado de Brasil (2017) Sinopses Estatísticas da Educação Básica.

Como pode ser observado no gráfico, a trajetória histórica apresenta crescimento robusto no número de matrículas na EPT, tanto na rede pública quanto na privada. Vale destacar que a partir de 2008 a curva passa a ser mais incisiva, contanto exatamente com a criação dos Institutos Federais.

É nítido o crescimento da Rede, se analisarmos o período de 2010 a 2015. Se estabelecermos um recorte por região, por exemplo, a região Norte apresentou um crescimento de $43 \%$ na sua expansão de campi pela região, e o Nordeste de 40,54\%, mas destacam-se as regiões Centro-Oeste e Sul, que respectivamente apresentaram expansão de $54,05 \%$ e $52,30 \%$, respectivamente, bem superior à média de crescimento nacional de 42,52\% (REIS JR., 2017).

O Brasil ainda carece da elaboração de um sistema de informações mais completo sobre a trajetória dos discentes que ingressam e são certificados nos diversos níveis de educação profissional, sobretudo a partir de 2011, com a criação do Programa Nacional de Acesso ao Ensino Técnico e Emprego (Pronatec), Lei $N^{\circ} 12.513$, de 26 de outubro de 2011. O Programa com mais de 8 milhões de matrículas, em um intervalo de 4 anos, tornou-se central na política pública na EPT, ocupando e centralizando todas as ações do governo Dilma no campo da educação profissional e tecnológica. O Pronatec viria a englobar a Rede Federal como um dos seus eixos, articular a gratuidade junto ao Siste- 
ma $S,{ }^{20}$ garantir repasses de recursos públicos para entes privados e públicos e estimular o financiamento de criação de escolas técnicas e profissionais na rede estadual de educação.

O Brasil aumentou consideravelmente a dotação orçamentária da área de educação profissional no âmbito do Ministério da Educação a partir da expansão da Rede Federal e com Programas como o Brasil Profissionalizado e o próprio Pronatec. Os dados da Tabela 1, a seguir, mostram que o orçamento quase decuplicou no período de 10 anos. A participação relativa quase dobrou no mesmo período e em 2014 era de mais de $10 \%$ do orçamento total do MEC. Isso revela a importância e a prioridade que foi dada a esta modalidade de educação, que nesse período incorporou 500 novas unidades físicas, além de apoiar algumas Secretarias Estaduais nos seus planos de expansão em termos similares aos da Rede Federal. O governo federal condicionou também os repasses aos governos estaduais no âmbito do Programa Brasil Profissionalizado para que a expansão fosse realizada nos mesmos moldes do sistema federal, ou seja, a partir do Ensino Médio integrado à Educação Profissional. Isso se refletiu na criação nos Estados de órgãos específicos para tratar da educação profissional (CASTIONI, 2018).

Tabela 1 - Orçamento do MEC e da Rede Federal (2005-2014), em milhões de reais

\begin{tabular}{|l|r|r|r|r|r|}
\hline UnidadeAno & $\mathbf{2 0 0 5}$ & $\mathbf{2 0 0 6}$ & $\mathbf{2 0 0 7}$ & $\mathbf{2 0 0 8}$ & $\mathbf{2 0 0 9}$ \\
\hline MEC & $21.022,57$ & $21.671,08$ & $27.580,00$ & $31.714,04$ & $40.524,63$ \\
\hline EPT & $1.430,63$ & $1.589,76$ & $2.007,85$ & $2.172,58$ & $2.289,99$ \\
\hline Relação \% & 6,81 & 7,34 & 7,28 & 6,85 & 5,65 \\
\hline & & & & & \\
\hline UnidadedAno & 2010 & $\mathbf{2 0 1 1}$ & $\mathbf{2 0 1 2}$ & $\mathbf{2 0 1 3}$ & $\mathbf{2 0 1 4}$ \\
\hline MEC & $50.903,73$ & $63.707,15$ & $74.280,37$ & $81.286,80$ & $94.490,61$ \\
\hline EPT & $4.148,23$ & $5.448,63$ & $6.713,82$ & $7.648,63$ & $9.912,70$ \\
\hline Relação \% & 8,15 & 8,55 & 9,04 & 9,41 & 10,49 \\
\hline
\end{tabular}

Fonte: BREZINSKI et al., 2015.

A partir do Programa de Aceleração do Crescimento (PAC), o esforço do governo Lula foi de fato o de conectar a educação profissional como estratégia de país. Bem ou mal coordenada, esta estratégia servia para atender à demanda por trabalho qualificado, ao mesmo tempo que a ampliação da renda e do consumo eram importantes ingredientes para gerar novas oportunidades de ocupação. Ao mesmo tempo que melhorava a qualificação profissional, oferecendo às empresas trabalhadores mais bem qualificados, o governo visava, com a expansão do crédito e de criação da demanda efetiva, a novas oportunidades para os trabalhadores. Esta era uma das dimensões das políticas do neodesenvolvimentismo. Não por menos, no período que vai de 2008 a 2012 o Brasil gerou 12 milhões de empregos e era recorrente o dilema do "apagão de mão de obra". Isso era estratégico, tanto para a desconcentração industrial como para a geração de novas oportunidades de trabalho para o Brasil continental. Até então a oferta de cursos de formação profissional estava muito concentrada na faixa litorânea do país e em poucas cidades grandes. A expansão para o interior do país e para o Nordeste brasileiro

\footnotetext{
${ }^{20}$ Conjunto de nove instituições de interesse de categorias profissionais vinculadas às Confederações Sindicais Patronais que têm responsabilidade sobre a formação profissional.
} 
trouxe outras perspectivas de crescimento da economia. Como estratégia governamental, portanto, as iniciativas da Argentina e do Brasil foram muito coerentes com a retomada do papel do Estado e a ampliação da oferta de educação pública para uma grande parcela da população.

\section{CONSIDERAÇÕES FINAIS}

Em termos de análise comparada, o que se percebe é a existência de uma problemática educativa comum a ambos os países, suscitada pela emergência de um sistema mundial no plano econômico, da educação e da cultura. Ambos os países estão situados no arco dos "sentidos da colonização" que defendeu Caio Prado Jr. (1969), quando da ruptura com o sentido único liberal, o surgimento da Comissão Econômica para a América Latina e o Caribe (Cepal), a retomada neoliberal e a virada no novo desenvolvimentismo.

Esse novo desenvolvimento significou uma ampliação de conceito e atuação com o período anterior, para ambos os países, retomando o sentido do protagonismo do Estado no jogo global e na criação de um ciclo local em favor da elevação material do crescimento econômico. Reclama-se, nesse ensejo, para a educação, uma importância determinante para a alavancagem do capital social necessário à tradição do capitalismo e da melhor organização da estrutura social local. Especificamente no campo da política de EPT, isso se vê refletido ao assumirem um papel mais relevante no financiamento e na definição de políticas públicas como possibilidade de atuação no território, e no caso do Brasil, retomando sua relação com o Ensino Médio Técnico integrado.

Esse reclame, no entanto, enfrenta sérios limites em alcançar seus objetivos relativos à melhoria social, no caso da aposta recente na EPT, ao partimos para uma análise do local ao global, na atualidade, como destaca Nóvoa (1995). No período recente, na travessia do final do século 20 para o novo século, não houve de fato uma ruptura com as políticas neoliberais - superávit primário, controle da inflação e câmbio flutuante mas um entendimento mais ampliado da primazia do papel do Estado como ente protagonista e, no caso particular tratado aqui, da ênfase em efetivar e ampliar direitos, como investimentos em políticas públicas de expansão da oferta de educação profissional e na melhor distribuição de renda e da redução da desigualdade social. Esse entendimento "alargado", no entanto, continua localizado dentro da ordem capitalista global e, portanto, sem romper verdadeiramente com a estrutura de reprodução local e global das desigualdades sociais.

Ao observar em cotejamento os casos de Brasil e Argentina, o que se tem é uma convergência do estágio local do processo de desenvolvimento dos Estados-nação e, especificamente, uma firme decisão de ampliar a oferta da EPT como forma de preparar melhor os trabalhadores. Nesse sentido, garantidas as necessidades prementes do capital-financeiro, o que foi percebido é uma retomada do sentido estratégico do protagonismo do Estado para o salto qualitativo e quantitativo do desenvolvimento local, seja observando a crescente dos estudos referentes, Bresser-Pereira $(2015,2016)$, Katz (2014a,b,c), Reis (2017) e tantos outros, seja nas próprias políticas de EPT gestionadas no período recente nesses países. 
Aqui analisadas, as iniciativas postas em prática entre 2003 e 2015 na Argentina e no Brasil, relativas à EPT, formam contornos do Novo Desenvolvimentismo na América Latina, enfrentando ao mesmo tempo problemas relativos à inserção do país no mercado internacional por meio do desenvolvimento do mercado interno, assim como a diminuição das desigualdades sociais por meio da educação.

\section{REFERÊNCIAS}

ARGENTINA. Constitución de la Nación Argentina: publicación del Bicentenario. 1. ed. Buenos Aires: Corte Suprema de Justicia de la Nación; Biblioteca del Congreso de la Nación; Biblioteca Nacional, 2010. 200p. Disponible en: http://bibliotecadigital.csjn.gov.ar/Constitucion-de-la-Nacion-Argentina-Publicacion-del-Bicent.pdf. Acceso en: 1ㅇjun. 2016.

ARGENTINA. Ley no 26.058. Ley de Educación Técnico Profesional. Ministerio de la Educación Ciencia y Tecnología. Septiembre 2005a. Disponible en: http://portal.educacion.gov.ar/consejo/files/2009/12/ley_ de_educ_tec_prof.pdf. Acceso en: 2 maio 2014.

ARGENTINA. Ley № 26.075. Ley de Financiamiento Educativo, 2005b. Disponible en: http://www.infoleg. gov.ar/infolegInternet/anexos/110000-114999/112976/norma.htm. Acceso en: 31 out. 2015.

ARGENTINA. Ley $n^{\circ}$ 26.206. Ley de Educación Nacional de la Argentina. Poder Ejecutivo Nacional. Ministerio de la Educación Ciencia y Tecnología. Diciembre 2006. Disponible em: http://portal.educacion.gov.ar/ consejo/files/2009/12/ley_de_educ_nac1.pdf. Acceso en: 2 maio 2014.

ARGENTINA. INET. Marcos de Referencia de Nivel Secundario. Disponible en: http://www.inet.edu.ar/index.php/niveles-educativos/educacion-secundaria-tecnica/marcos-de-referencia-de-nivel-secundario/. Acceso en: 20 jun. 2017.

ARGENTINA. INET. Censo nacional de último año de educación técnico profesional 2009: metodología y resultados generales. Buenos Aires: Ministerio de Educación de la Nación, 2011. 96p. V. 4.

ARGENTINA. INET. La técnica ganada. Conmemoración de los 10 años de la Ley de Educación Técnico Profesional. Buenos Aires: Ministerio de Educación de la Nación; Inet, 2015a.

ARGENTINA. INET. La Educación Técnico Profesional en cifras 2015. Buenos Aires: Ministerio de Educación de la Nación; Inet, 2015b. 38p.

ARgENTINA. INET. Conmemoración de los 10 años de la Ley de Educación Técnico Profesional. Buenos Aires: Ministerio de Educación de la Nación; Inet, 2015c. 100p.

ARGENTINA. INET. Evaluación de Capacidades Profesionales en la ETP de Nivel Secundario. Documento aprobado por Resolución No. 266/15 CFE. Buenos Aires: Ministerio de Educación de la Nación; Inet, 2015d. 64p.

ARGENTINA. INET. Encuesta Nacional de Trayectoria de Egresados. Buenos Aires: Ministerio de Educación de la Nación; Inet, 2015e. 120p.

BRASIL. Lei no 11.892 de 29 de dezembro de 2008. Institui a Rede Federal de Educação Profissional, Científica e Tecnológica, cria os Institutos Federais de Educação, Ciência e Tecnologia, e dá outras providências. Diário Oficial da União, Brasília, 30 dez. 2008.

BRASIL. Lei no 13.005 de 2 de junho de 2014. Aprova o Plano Nacional de Educação - PNE - e dá outras providências. Diário Oficial da União, Brasília, 26 jun. 2014a. Disponível em: http://www.planalto.gov.br/ ccivil_03/_ato2011-2014/2014/lei/l13005.htm. Acesso em: 13 dez. 2017.

BRASIL. Lei no 12.513 de 26 de outubro 2011. Institui o Programa Nacional de Acesso ao Ensino Técnico e Emprego (Pronatec). Diário Oficial da União, Brasília, 27 out. 2011.

BRASIL. Decreto no 2.208, de 17 de abril de 1997. Regulamenta o §2o do art. 36 e os artigos 39 a 42 da lei 9.394, de 20 de dezembro de 1996, que estabelece as diretrizes e bases da educação nacional. Diário Oficial da União, Brasília, 18 abr. 1997a. Disponível em: http://www.planalto.gov.br/ccivil_03/decreto/ d2208.htm. Acesso em: 2 nov. 2017.

BRASIL. Decreto no 5.154, de 23 de julho de 2004. Regulamenta o § 20 do art. 36 e os arts. 39 a 41 da Lei n. 9.394, de 20 de dezembro de 1996, que estabelece as diretrizes e bases da educação nacional, e dá outras providências. Diário Oficial da União, Brasília, 26 jul. 2004. Disponível em: http://www.planalto.gov. br/ccivil_03/_ato2004-2006/2004/decreto/d5154.htm. Acesso em: 12 dez. 2017.

BRASIL. Decreto no 6.302, de 12 de dezembro de 2007. Institui o Programa Brasil Profissionalizado. Diário Oficial da União, Brasília, 13 dez. 2007b. Disponível em: http://www.planalto.gov.br/ccivil_03/_ato20072010/2007/decreto/d6302.htm. Acesso em: 2 nov. 2017. 
BRASIL. MEC. Plano de Desenvolvimento da Educação. Razões, Princípios e Programas. Brasília: MEC, $2007 a$.

BRASIL. MEC. Plano de Expansão da Rede Federal de Educação Profissional e Tecnológica. Brasília: MEC, 2006.

BRASIL. MEC/INEP. Taxa de distorção idade série por região. 2014b.

BRASIL. MEC/INEP. Sinopses Estatísticas da Educação Básica. Disponível em: http://inep.gov.br/sinopses-estatisticas-da-educacao-basica. Acesso em: dez. 2017.

BRASIL. MEC/SETEC. Relatório de Gestão. Brasília: MEC, 2013.

BRESSER-PEREIRA, Luiz Carlos. Teoria novo-desenvolvimentista: uma síntese. Cadernos do Desenvolvimento, Rio de Janeiro, v. 11, n. 19, p. 145-165. jul./dez. 2016.

BRESSER-PEREIRA, L. C. A construção política do Brasil. São Paulo: Editora 34, 2015.

BRESSER-PEREIRA, L. C. Do antigo ao novo desenvolvimentismo na América Latina. In: BRESSER-PEREIRA, L. C.; PRADO, D. (org.). Desenvolvimento econômico e crise. Rio de Janeiro: Contraponto, 2012.

BREZINSKI, M. A. S. et al. A evolução orçamentária da rede federal de educação profissional, científica e tecnológica. In: Boletim iDEIA, Florianópolis: IFSC, n. 1, 2015. Disponível em: https://caco.ifsc.edu.br/images/jornalismo/Boletimideia/Boletim_iDEIA_1_2015.pdf. Acesso em: 24 ago. 2017.

CASTIONI, R. Programa Brasil profissionalizado: a oferta de cursos técnicos na Bahia e no Acre. Trabalho Necessário, Niterói, RJ, ano 16, no 30/2018. Disponível em: www.http://periodicos.uff.br/trabalhonecessario.

DALLABRIDA, V. R. Desenvolvimento regional: Por que algumas regiões se desenvolvem e outras não? 1a Impressão. Santa Cruz do Sul: Edunisc, 2011.

COWEN, R.; KAZAMIAS, A. Introdução editorial conjunta. In: COWEN, R.; KAZAMIAS, A. M.; UNLTERHALTER, E. (org.). Educação comparada: panorama internacional e perspectivas. Brasília: Unesco; Capes, 2012. p. 13-17. 1 v.

FELDFEBER, M.; GLUZ, N. Las políticas educativas en Argentina: herencias de los " 90 ", contradicciones y tendencias de "nuevo signo". Revista Educação \& Sociedade, Dossiê: As políticas educacionais dos novos governos na América Latina, Campinas, v. 32, n. 115, p. 339-356, abr./jun. 2011.

FERREIRA, M. C. P. Industrialização, economias do conhecimento e mudança educacional: um comentário sobre a Argentina e o Brasil. In: COWEN, R.; KAZAMIAS, A. M.; ULTERHALTER, E. (org.). Educação comparada: panorama internacional e perspectivas. Brasília: Unesco; Capes, 2012. p. 635-658. V. 1.

GALLART, M. A. La escuela técnica industrial en Argentina: ¿un modelo para armar? Montevideo: OIT; Cinterfor, 2006.

GAMBINA, J. C. Crisis del capital 2007-2013. La crisis capitalista contemporánea y el debate sobre las alternativas. Buenos Aires: Fundación Investigaciones Sociales y Políticas, 2013.

KALOYIANNAKI, P.; KAZAMIAS, A. M. Os primórdios modernistas da educação comparada: o tema protocientífico e administrativo reformista-meliorista. In: COWEN, R.; KAZAMIAS, A. M.; ULTERHALTER, E. (org.). Educação comparada: panorama internacional e perspectivas. Brasília: Unesco; Capes, 2012. p. 25-54.

KAZAMIAS, A. Homens esquecidos, temas esquecidos: os temas histórico-filosófico-culturais e liberais humanistas em educação comparada. In: COWEN, R.; KAZAMIAS, A. M.; UNLTERHALTER, E. (org.). Educação comparada: panorama internacional e perspectivas. Brasilia: Unesco; Capes, 2012. p. 55-81. 1 v.

KATZ, C. Qué es el neo-desarrollismo? I - Una visión crítica. Economía. 2014a. Disponible en: http://katz. lahaine.org/?cat=1. Acceso en: ago. 2014.

KATZ, C. Qué es el neo-desarrollismo? II - Una visión crítica. Argentina y Brasil. 2014b. Disponible en: http://katz.lahaine.org/?cat=1. Acceso en: ago. 2014.

KATZ, C. Qué es el neo-desarrollismo? III - Una visión crítica. Teoría y política. 2014c. Disponible en: http:// katz.lahaine.org/?cat=1. Acceso em: ago. 2014.

LÓPEZ-VELARDE, J. C. Introducción. In: LÓPEZ-VELARDE, J. C. (coord.). Teoría y desarrollo de la investigación en educación comparada. México, D.F.: Plaza y Valdés, 2000. p. 11-24.

MADURO SILVA, D. Estudo comparado sobre evasão escolar na educação profissional - Brasil e Argentina. 2018, 344p. Tese (Doutorado em Educação) - Faculdade de Educação, Universidade Federal de Minas Gerais, Belo Horizonte, 2018.

MATTHEOU, D. O paradigma científico na educação comparada. In: COWEN, R.; KAZAMIAS, A. M.; UNLTERHALTER, E. (org.). Educação comparada: panorama internacional e perspectivas. Brasília: Unesco, 2012.

METRO, Canal televisivo. El impacto de la educación técnica para el desarrollo del país. In: Programa Trabajo Argentino. Exibido em 23/4/2015. 
MIRANDA, A.; CORICA, A. El vínculo entre la educación secundaria y el mundo del trabajo: tensiones entre su complementariedad y su mutua exclusión. In: DORE, R.; ARAÚJO, A. C; MENDES, J. S. (org.). Evasão na educação: estudos, políticas e propostas de enfrentamento. Brasília: Instituto Federal de Brasília, 2014. p. 293-315.

MORAES, G. H.; KIPNIS, B. Identidade de Escola Técnica vs Vontade de Universidade nos Institutos Federais: uma abordagem histórica. Linhas Críticas, v. 23, n. 52, p. 693-716, Brasília, DF, jun./set. 2017. Disponível em: https://doi.org/10.26512/lc.v23i52.22884. Acesso em: fev. 2018.

NóVOA, A. Modelos de análise em educação comparada: o campo e a carta. In: Les Sciences de l'education pour l'ère nouvelle, n. 2-3, 1995. (Mimeo. traduzido por Madeira, A. I.).

OTERO, A. Educación técnico profesional, política y gestión de la modalidad para el caso argentino. In: DORE, R. et al. Evasão na educação: estudos, políticas e propostas de enfrentamento. Brasília: Instituto Federal de Brasília, 2014. p. 57-76.

OTERO, A. Escuela media y abandono escolar en Argentina: aproximaciones a un debate pendiente. Educação em Revista, v. 27, n. 3, Belo Horizonte, dez. 2011. Disponible en: http://www.scielo.br/scielo.php?script=sci_arttext\&pid=S0102-46982011000300008. Acceso en: 15 nov. 2014.

PRADO JÚNIOR, C. História econômica do Brasil. São Paulo: Brasiliense, 1969.

RANGEL, I. A história da dualidade brasileira. Revista de Economia Política, v. 1, n. 4, out./dez. 1981.

REIS JR., R. de L. Os limites da experiência de Estado desenvolvimentista no Brasil (2003-2015): o caso dos Institutos Federais. 2017. Tese (Doutorado) - Universidade Federal de Brasília, Programa de Pós-Graduação em Educação, Brasília, 2017.

RUST, V. D. et al. Research strategies in comparative education. Comparative Education Review, The University of Chicago Press, v. 43, n. 1, p. 86-109, feb. 1999. Disponível em: http://www.jstor.org/stable/1189215. Acesso em: 5 mar. 2012.

SAFOCADA, F.; VASSILADES, A. Las leyes de educación en los comienzos del siglo XXI: Del neoliberalismo al postconsenso de Washington en América del Sur. In: Educação \& Sociedade, Campinas, v. 32, n. 115, p. 287-304, abr./jun. 2011.

SCHRIEWER, J. Sistema mundial y redes de interrelación: la internacionalización de la educación y el papel de la investigación comparada. In: PEREYRA, M. A. et al. (comp.). Globalización y descentralización de los sistemas educativos. Barcelona: Ed. Pomares-Corredor, 1996.

SOSA, M. L. Las cifras de la Educación Técnica Profesional a 10 años de la Nueva Ley. In: Revista Novedades Educativas, n. 306, jun. 2016a. (Dossier ¿Qué hay de nuevo en la formación para el trabajo de jóvenes?). SOSA, M. L. Educación técnica e inserción laboral en Argentina. Ventajas e limitaciones del título técnico. In: JACINTO, C. et al. Protección social y formación para el trabajo de jóvenes en la Argentina reciente: entramados, alcances y tensiones. Buenos Aires: Instituto de Desarrollo Económico y Social, 2016b. 